\title{
El hombre y sus epidemias a través de la historia
}

\author{
WALTER LEDERMANN D.*
}

\section{The Man and his epidemics through the History}

\section{Pánico y huida}

Hace unos veinte mil años, en un tempestuoso atardecer, el hechicero cro-magnon regresaba de un retiro de tres días en el monte, donde había estado recolectando yerbas mágicas, cuando le informaron que uno de los hombres había llegado enfermo de una larga jornada cinegética. Seguro de su poder curativo -la ignorancia hace audaces a los médicosse recubrió con su vestimenta de venado y fue a verlo. Apartó el cuero que tapaba la entrada de la caverna e iluminó al enfermo con su antorcha. De inmediato dio un respingo, retrocedió espantado, ordenó levantar el campamento y huir hacia un incierto fin en medio de la noche. En la pustulosa cara del enfermo había reconocido la viruela -o alguna peste similar de la época- cuya horrorosa imagen había recibido a través de los relatos sucesivos de su padre y de su abuelo, y sabía que la muerte era inevitable.

En 1994, en nuestra Unidad de Infecciosos, solicitamos a un talentoso especialista, hombre muy culto y racional, que evaluara un pequeño paciente. Accediendo de buena gana, contempló un rato al niño a través del vidrio y, en el momento de abrir la puerta corrediza, preguntó por qué estaba aislado. Al escuchar la palabra SIDA quedó con el pie en alto, alterado el rostro; luego de unos segundos, echó pie atrás y dijo que bastaba con lo que le habían contado, no siendo necesario el examen físico.

Habíamos perdido en Chile, país médicamente desarrollado, este temor irracional que acompaña a las pestes y que deriva de la certeza de poder ser atacado en cualquier momento por una enfermedad fatal, irreversible y atroz. Y no sólo en Chile, sino en todos los países más o menos avanzados el hombre moderno está convencido que la medicina todo lo cura, careciendo de recursos espirituales para comprender y enfrentar la existencia de una epidemia altamente letal. El especialista que nos visitaba era un hombre muy instruido y sabía perfectamente cómo se contagia el SIDA y que, por lo tanto, no estaba expuesto, pero pudo más el temor ancestral que la razón.

Esta ha sido siempre la primera humana reacción a las terribles pandemias: pánico. Un miedo súbito, extraordinario, que oscurece la razón. Al pánico sigue la huida, como consecuencia inevitable. En me- dio del pánico, sin embargo, siempre han existido hombres curiosos que han antepuesto la observación a su propio temor. A ellos, oscuros o famosos, debemos los avances experimentados. Pero en todas las pandemias, este terror irracional ha hecho retroceder momentáneamente en algún punto a la medicina y a la humanidad, por detrás de logros y de conocimientos ya establecidos.

La segunda reacción, ya en medio de la catástrofe es la búsqueda de una causalidad. Para el hombre primitivo -y aun para el moderno- hay simultáneamente una culpabilidad, de manera que la epidemia es siempre un castigo.

\section{Primeras observaciones sobre transmisión}

La peste bubónica -la peste negra, la peste por antonomasia- causó sucesivas pandemias, dejando los primeros registros más o menos confiables, capaces de ilustrar cómo se fueron dando los sucesivos pasos en el entendimiento y control de la situación. Aunque en el libro de Samuel hay descripciones que pudieran corresponder a esta patología, y existen antiguas referencias de Tucídides, Hipócrates y de Cipriano (siglo III d.C.), la primera gran pandemia se registró en el mundo antiguo en tiempos del emperador Justiniano, en el siglo VI d.C.; duró sesenta años y terminó mezclada con viruela. Luego tenemos la celebérrima muerte negra, que asoló toda Europa entre 1347 y 1382, habiéndose iniciado, de acuerdo a la mayoría de las descripciones, en Catay (China). Desde allí pasó a Europa, donde sólo respetó a Islandia, no así, a la ya descubierta Groenlandia, para extenderse luego a Arabia y Egipto (Tabla 1).

\section{Tabla 1. Epidemias de peste bubónica}

\footnotetext{
1. Cipriano SIGLO III d.C.

2. Justiniano SIGLO VI d.C: 60 años de peste

3. Peste negra 1347-1382 25 millones de muertos

4. Italia-Alemania SIGLO XVI

5. Inglaterra 1665 el año de la peste, de D. Defoe

6. Viena 1678 Actuación del Dr. Sorbeit
}

Los médicos papales Chalin de Vinario y Guy de Chauliac, que hicieron muy buenas descripciones, estiman los muertos en 25 millones, lo que constituía

\footnotetext{
* Conferencia inaugural del Congreso Chileno de Infectología 1996, Viña del Mar ).
} 
por entonces un cuarto de la población total. El mismo Chalin de Vinario anota como se fue extinguiendo la peste y mejorando la sobrevida en los sucesivos rebrotes:

1348: enferman 2/3 y no sobrevive ninguno.

1361: enferma la mitad y sobreviven algunos.

1371: enferma $1 / 10$ y muchos mejoran.

1382: enferma $1 / 20$ y la mayoría cura.

Pese a la acuciosidad y seriedad de estos autores, el público recuerda más al Decamerón de Boccaccio, que es más entretenido y regocijante, cuyo único aporte importante es dejar constancia que ya existía el concepto de aislamiento y una noción de contagio: basta mirar a un enfermo para contraer la peste, afirma Boccaccio.

El médico que atiende a los apestados se cubre con una máscara protectora y aspira perfumes para no contagiarse, hasta alcanzar la imagen que veremos en 1720 en una ilustración del libro del Dr. Francisco Chicoynau Der Pestarzt, un infectólogo, ataviado con una larga túnica y la cabeza recubierta con una máscara, terminada en una mascarilla que recuerda las actuales hocico de perro.

\section{Consecuencias político-sociales}

Según el notable historiador médico Laín Entralgo, la peste negra tuvo tres consecuencias importantes, además de las políticas (terminó con la Guerra de Cien Años):

- Una gran recesión en Europa, no sólo demográfica, sino económica.

- Una exaltación de ciertas prácticas religiosas viciosas, como las procesiones de flagelantes, con un claro contenido social: la muerte nivela a ricos y a pobres. Los flagelantes hicieron correr la voz de que eran los judíos los causantes de la peste, con el consiguiente asesinato de miles de ellos. El Papa, que era inteligente y veía como en Avignon la peste estaba lejos de respetar a los judíos, emitió una tardía e inútil bula declarando su inocencia.

- Como contrapartida, otros vivieron una exaltación de los placeres mundanos, ante la fugacidad de la vida (carpe diem). En la primera jornada del Decamerón, Pampinea solicita a sus jóvenes amigos que nadie traiga noticias que no sean alegres.

\section{Guerra, política y salud}

Si la peste exaltó en algunos los más nobles valores humanitarios, en otros despertó ideas malvadas. En 1350 los tártaros sitiaban Caffa, un puesto comercial genovés en el Mar Negro (hoy Feodosiya, en Ucrania). Los sitiadores habían viajado con la peste desde Catay, y a través de Mongolia. Su jefe, el khan Janibeg, concibió la brutal idea de catapultar sus cadáveres sobre las murallas de la ciudad: murieron así sitiados y sitiadores. Algunos genoveses sobrevivieron y llevaron 12 galeras -y muchos microbiosa Messina, Sicilia, transportando la peste al continente europeo. De acuerdo a esta versión, así habría sido el comienzo de la gran epidemia de peste negra en Europa. No obstante, al llegar los genoveses a Messina, la peste les llevaba dos años de ventaja.

En el siglo XIV eran populares las guerras entre Inglaterra y Francia, conformando lo que se llamó la guerra de cien años. Los ingleses habían desarrollado un poderoso arco - el arco largo - capaz de traspasar una cota de malla: a doscientos cuarenta metros la lluvia de flechas eran tan tupida, que parecía como si nevara. Los ingleses, al mando del famoso "Príncipe Negro" (famoso por su brutalidad en la guerra ) enfrentaron a Felipe de Francia en la selva de Crecy, el 26 de agosto de 1346. Los franceses, queriendo neutralizar el poder del arco largo, habían contratado una compañía de ballesteros genoveses. Cuando los genoveses avanzaban a paso lento para tomar distancia (habían marchado 29 kilómetros a pie), una bandada de cuervos atravesó el cielo graznando siniestramente.

- ¡Mal presagio! - gimieron los genoveses.

- ¡Buen presagio! - exclamaron los ingleses.

Cayó entonces un sorpresivo chaparrón, mojando e inutilizando las cuerdas de las ballestas. Seis mil arqueros ingleses fusilaron a los genoveses, que huyeron hacia las filas francesas.

- ¡Maten a esos pillos! - ordenó Felipe, señalando a los ballesteros, a fin de facilitar el ataque de su caballería.

Y así se hizo. Sería la mayor victoria de los ingleses sobre sus tradicionales enemigos hasta el 25 de octubre de 1415 , en que les darían una paliza todavía mayor en Azincourt, batalla magistralmente narrada por Shakespeare en Henry $V$. El camino de Francia quedaba abierto, pero... un inesperado enemigo iba a diezmar ambos ejércitos y poner una larga pausa en la guerra: la peste. De manera que la Muerte Negra derrotó al Príncipe Negro y el arco largo cayó ante el bacilo corto...

En el siglo XVII encontramos las figuras del médico belga Paul de Sorbeit y del príncipe Ferdinand von Schwarzenberg, el príncipe de la peste, y vemos por primera vez razones políticas antepuestas a razones de salud pública. En 1678, el Dr. Sorbeit, un médico de Viena, advirtió los primeros casos de peste, importados de Turquía. Informó al Gobierno, pero como se celebraba el cumpleaños del príncipe heredero y todos los preparativos estaban hechos, las autoridades informaron los casos sólo como fiebre alta. La fiesta se celebró y los distintos embajadores se llevaron la peste a sus respectivas naciones. El Rey Leopoldo, aterrado por lo que había hecho, viajó en peregrinación al santuario de Maringel, a $85 \mathrm{Km}$ de Viena... y la peste viajó con él, de manera que Sorbeit la denominó pestis ambulans. El príncipe heredero Ferdinand, por su parte, se caracterizó por su denodada lucha contra la enfermedad, siendo célebre la anécdota de haber recogido un cadáver que transportaba el carretero de la muerte, y que éste no quería echar de nuevo al carro. El príncipe castigó severamente al Magíster del hospital, por ampliar la cifras de los enfermos y de sus días de estadía, a fin de cobrar mayor subsidio estatal, así como por apropiarse de algunos legados. En cam- 
bio, honró a Sorbeit y a otros 28 médicos fallecidos en plena labor.

Desde entonces comienza la extinción. En el siglo pasado aún quedaba peste endémica en Turquía, Egipto, India, China y Rusia, estableciéndose cuarentena para los viajeros provenientes de esos países.

\section{Aislamiento: antecedentes literarios}

Durante las primeras pandemias ya se había observado que el riesgo de enfermar aumentaba al aproximarse a los enfermos o, dicho de otra manera, que los enfermos irradiaban el mal. Nació así el concepto del contagio aéreo. Avicena, el famoso médico del siglo XI, había reparado en que, antes del inicio de la peste, las ratas comenzaban a morir en las calles, pero ni él ni nadie en mucho siglos encontró una explicación, aunque Atanasius Kircher en 1659, vio los animaliculus al microscopio. Luego se observó que las ropas usadas por quienes habían fallecido también podían trasmitir la enfermedad. Estas observaciones fueron confirmadas ampliamente durante la peste negra, dada su duración y extensión, que permitieron hacer muchas constataciones. Las consecuencias fueron dos conceptos profilácticos: el aislamiento (huida) y el acordonamiento (cuarentena, protección de fronteras) (Tabla 2).

Tabla 2.

\section{¿Contagio?}

Eludir a los enfermos

Sepultar o quemar a los muertos

Abandonar los lugares

Acordonar los lugares

Del aislamiento tomamos tempranamente nota en Bocaccio. Recordemos como unas nobles damas y gentiles caballeros huyen de la ciudad y se aislan en una villa, donde matan el tiempo relatándose historias picarescas. Huyen así del mal aire que rodea a los enfermos y a los muertos. Mucho más tarde, Daniel Defoe, autor conocido más que todo por su Robinson Crusoe, aporta otros antecedentes en $E l$ año de la peste, donde relata cómo Inglaterra, que hasta entonces se había escapado de la enfermedad por su insularidad, fue finalmente afectada por una gran epidemia en 1665. Algunos ingleses, imitando a los personajes de Bocaccio, pusieron agua por medio y se fueron a los buques anclados mar afuera, donde perecieron igual, pues llevaban la bacteria con ellos. Defoe relata las crueles prácticas de aislamiento adoptadas, que condenaban a muerte a familias enteras, obligándolos a permanecer encerrados en sus casas junto a los moribundos, con guardias en las puertas delantera y trasera, los que muchas veces fueron asesinados.

\section{Cordón sanitario y cuarentena}

La cuarentena nació en 1374, con el edicto de
Reggio, ciudad de Módena, Italia. En realidad fue un cordón sanitario, pues el término cuarentena derivó en término marítimo, aplicándose un período de aislamiento a los buques que llegaban de puertos de mala fama médica. Este período llevaba implícita la idea del período de incubación. El primer puerto en que se decretó cuarentena (que fue sólo treintena: luego se ampliaría) fue Ragusa (hoy Dubrovnik, Bosnia-Herzegovina, sobre el Adriático) en 1377. Seis años después, Marsella aumentó el plazo a los cuarenta días. En el siglo XV este período de observación o cuarentena hizo nacer el lazareto, también en Marsella, 1476, lugar complementario donde los pasajeros debían permanecer en espera que pasase el período de contagio arbitrariamente establecido. Con el tiempo llegaron a establecerse complejos reglamentos. Según el puerto de procedencia o los puertos que hubiera tocado en su viaje, el barco se calificaba de patente "limpia" o "sucia". Si era "sucia", los objetos debían quedar en la cubierta del barco, oreándose " al sereno" (período de sereinage), los pasajeros sanos cumplir cuarentena en el lazareto y los enfermos ir al hospital. Según la enfermedad, los plazos variaban entre 8 y 30 días. ¡En 1784, Marsella imponía 50 días de cuarentena a los buques procedentes de Túnez y Argel ! Luego del período de serenaige, barco, bártulos y enseres se desinfectaban con vapores de cloro (Tabla 3).

\section{Tabla 3}

Cuarentena, siglos XV a XIX

(8 a 30 días, según patología)

Patente limpia: desembarco libre

Patente sucia

Objetos: sereneige en cubierta

Pasajeros sanos: al lazareto

Enfermos: al hospital

En el siglo XIX ya había fuertes polémicas sobre la utilidad de la cuarentena. En 1872, en Italia, 800 barcos permanecieron en cuarentena, con fuertes pérdidas económicas, sin que enfermara nadie a bordo. En 1799, Napoleón desembarcó sus tropas provenientes de Oriente, en Frejus, Francia, haciendo caso omiso de la cuarentena, pues el tiempo era oro. Inglaterra suspendió la cuarentena y la Academie francaise declaró que la fiebre amarilla y la peste no eran infecciosas. Pero EE.UU. demostró un éxito total evitando la importación de la fiebre amarilla, de manera que la cuarentena continuó en Europa hasta principios del siglo XX.

Los cordones sanitarios en las fronteras eran más difíciles de mantener. En 1530 fueron quemados en Italia algunos comerciantes que burlaron el cordón. Dos siglos después, en 1720, Inglaterra estableció un cordón de hierro para varios de sus puertos, debiendo luego echar pie atrás, pues la falta de abastecimiento hacia el interior estaba provocando "una penuria real, por evitar una calamidad probable". Por decreto del gobierno alemán del 29 de 
enero de 1879 prohibiose el ingreso desde Rusia de: "ropas interiores y de camas y vestidos usados, cueros, pieles, vejigas e intestinos frescos o secos, fieltros, cepillos, plumas, caviar, peces y bálsamo de Sarepta". En 1996, se prohibió la internación en toda Europa de carne de vacuno desde las islas británicas y se asesina a todo el ganado en pie, por una publicación afirmando " que no se puede descartar la trasmisión de la enfermedad de las vacas locas al hombre", con lo cual parece ponerse en manifiesto cierto retroceso irracional.

El imperio austro-húngaro llevó al extremo los cordones sanitarios en su frontera con Turquía, en el siglo XVIII. Cada hombre tenía la obligación de cuidar la frontera 149 días al año, de manera que en 1799 había 692 puestos, con 4.000 hombres, que aumentaban a 7.000 y hasta 11.000 si había casos en Estambul: estaban tan cerca uno de otro, que de día podían verse y de noche llamarse (Tabla 4).

\section{Tabla 4. Cordón sanitario}

1374. Italia. Edicto de Reggio.

1530. Italia. Quema de evasores

1879. Alemania. Prohíbese ingreso de Rusia de ropas, pieles, cepillos, intestinos, peces, caviar y bálsamo de Serepta.

1996. Europa. Prohíbese el ingreso de carne desde las islas británicas.

\section{Saneamiento ambiental}

Existía una confusa idea sobre el "mal aire" y la "mala agua". Durante la peste negra se culpó a los judíos de haber "envenenado los pozos". John Snow, el célebre obstetra de la reina Victoria, fue quien puso en claro la trasmisión acuática, a raíz del cólera en Inglaterra, siglo XIX. Snow advirtió que el cólera se expandía desde los buques Támesis abajo, de manera que la compañía de agua potable que la sacaba río arriba difundía menos la enfermedad que aquella que la sacaba río abajo, observación que demostró en un hermoso trabajo comparativo.

\section{Inmunización}

Las epidemias permitieron a algunas personas inteligentes observar que quienes habían sobrevivido a la enfermedad, no volvían a enfermar. La práctica de la variolización, esto es, la inoculación en la piel del contenido de una pústula de un enfermo, era ya milenaria en India cuando Lady Montagu la popularizó en Europa. Muchos morían de la variolización, entre ellos uno de los indios yaganes que Fitz-Roy llevó a Inglaterra en 1830. Ya se empleaba el método, como complemento de la cuarentena. La visión genial de Jenner, en 1776, de que podía inmunizarse sin peligro reemplazando la pústula de viruela por una de vacuna, terminaría por imponerse, aunque él mismo prefirió variolizar a su hijo y no vacunarlo... La vacunación ha terminado con los cordones sanitarios, reduciéndolos a medi- das más racionales, como las empleadas durante la reciente amenaza de importación de cólera desde Perú.

\section{Origen de las pandemias}

Queda un problema no resuelto. ¿Cómo se generan las epidemias? No había sífilis en Europa antes del siglo XV, al menos no en forma masiva: se culpó a América. No había SIDA antes de 1981: se culpó a Haití. No había cólera antes de 1830: se culpó a India. Pero en India, de acuerdo a registros británicos muy serios, nunca "había habido enfermedad semejante". Cuando ya era un dogma que sólo el serotipo O 1 de Vibrio cholerae provocaba la enfermedad, ha surgido ahora en Bengala un serotipo totalmente nuevo, el 0139, que amenaza causar una nueva pandemia. Entonces... ¿aparecen nuevas bacterias o se modifican las anteriores? ¿Vuelve el castigo divino? (Tabla 5).

Tabla 5. Culpar a otros: La historia siempre se repite

La peste negra vino de Catay : los chinos fueron

La sífilis vino de las Indias : roña española, mal francés, peste napolitana

El SIDA nació en Haití ; mentira, en África.

\section{Resumen}

Llegamos al resumen de hitos respecto a las observaciones o intuiciones y sus consecuencias

- Naturaleza contagiosa: escape.

- Aislamiento forzado o voluntario.

- Período de contagio: cuarentena.

- Agente infectante (emanación): desinfección.

- Inmunidad de los sobrevivientes: variolización.

- Vías de trasmisión: medidas sanitarias.

- Los microbios: vacunas, antitoxinas, antibióticos.

- Retorno al principio: VIH, Ébola-Reston, Hantavirus.

Reaparecen las escenas de terror con el Ébola en los hospitales africanos, donde no quieren atender a los enfermos. Los laboratorios rehusan trabajar el virus, alegando insuficientes condiciones de seguridad. Con el conocimiento adquirido a través de siglos de terror y de mortandad, hoy los pasos son más acelerados, pero las reacciones son las mismas, como lo ilustra el SIDA, que recuerda a todas las pestes: la muerte al azar (cólera), el temor y el rechazo (el perro rabioso), la segregación y la muerte en vida (lepra), el castigo a la vida licenciosa (la sífilis), la muerte inevitable, lenta y contagiosa (tuberculosis) y los hombres de iglesia, abriendo sus brazos sin temor al contagio, allí donde los médicos vacilan.

Se cierra el ciclo que esbocé al comienzo y que une, en una misma reacción visceral, al hechicero cro-magnon con el médico especialista. Sin embargo, de esta visión del pasado surge una visión optimista: siempre el hombre ha terminado por prevalecer frente a las más tremendas epidemias. 


\section{Bibliografía}

1.- Behn F, Wölfel D. Historia del arte universal, Moreton S.A., Bilbao, sin fecha.

2.- Ludwig von B. Concepción biológica del cosmos. Ediciones de la Universidad de Chile, Santiago, 1963.

3.- Boccaccio. El Decamerón. El Ateneo, Buenos Aires, 1960.

4.- Burnet, Sir Macfarlane. Historia de las enfermedades infecciosas, Alianza Editorial, Madrid, 1967.

5.- Churchill, Sir Winston. Historia de Inglaterra y de los pueblos de habla inglesa, Peuser, Buenos Aires, 1958.

6.- Defoe D. El año de la peste, Seix Barral, Barcelona, 1969.

7.- Diels H. La técnica antigua, Zig-Zag, 1948.

8.- Eulenburg, A. Diccionario enciclopédico de medicina y cirugía prácticas. Jubera, Madrid, 1886.

9.- Federmann R. La alquimia. Bruguera, Barcelona, 1972.

10.- Haggard H. El médico en la historia, Sudamericana, Buenos Aires, 1952.

11.- Illich I. Medical Némesis, the expropiation of health,
Calder \& Boyar, London, 1975.

12.- Inglis B. Historia de la Medicina, Grijalbo, Barcelona, 1968.

13.- Laín Entralgo P. Historia de la Medicina, Salvat, Barcelona, 1978.

14.- Medical Research Council. A system of bacteriology in relation to medicine, His Majesty's St.Office, London, 1929.

15.- Monod J. Le hasard et la necessité: Essai sur la philosophie naturelle de la biologie moderne, Tusquets, Paris, 1970.

16.- Muntaner R. Crónica. Alianza Editorial, Madrid, 1970.

17.- Peltola H. Vacunación y enfermedades infecciosas, Connaught Res. Labs, Ontario, 1996 (en prensa).

18.- Riquer M de, Valverde J M. Historia de la literatura universal, Planeta, Barcelona, 1968.

19.- Seignobos Ch. Historia de la civilización contemporánea, 6a. edición. Librería de la V. de Ch. Bouret, Paris, 1916.

20.- Trousseau A. Clinique Médicale de l'Hotel Dieu de Paris, J.B. Ballière et Fils, Paris, 1865. 